\title{
A Comparative Study between Laparoscopic Hernia Repair and Open Lichtenstein's Hernia Repair
}

\author{
Dr. Arjun Athmaram ${ }^{1}$, Dr. Saptarshi Paul ${ }^{2}$, Dr. Harishchandra $B^{3}$ \\ Department of Surgery, Yenepoya Medical College Hospital, Deralakatte, Mangalore, Karnataka, India
}

\begin{abstract}
This is a prospective study involving 50 cases of unilateral inguinal hernia admitted in Yenepoya Medical College, Mangalore, Karnataka, India, 25 of whom underwent open Lichtenstein's repair and the remaining, laparoscopic Total Extraperitoneal (TEP) Repair. The study deals with a comparison of the effectiveness of these two types of repair. 50 cases of unilateral inguinal hernia admitted in Yenepoya Medical College, Mangalore, were selected on the basis of convenience sampling method. Adults (>15 years) consenting for randomized trials and having either unilateral direct or indirect inguinal hernia were included. They were randomly chosen for Lichtenstein's or TEP repair and the results were compared on the basis of the following outcome measures :i) duration of operation (in mins), ii) post operative pain ( in days), iii) length of hospital stay ( in days), iv) post operative complications like haematoma, seroma, v) time to return to usual activities and vi) cost comparison. The outcomes were evaluated and compared with standard published literature. The mean duration of surgery for Lichtenstein's repair was 62.2 minutes whereas for TEP was 72.4 minutes. Duration of post operative pain was more (2.8 days) for open repair than 1.48 days for TEP repair; same being for post operative stay (5.12 days for Lichtenstein's repair and 2.6 for TEP). Time of returning to normal work was 43.72 days for Lichtenstein's repair and 25.6 days for TEP repair. However, TEP repair was approximately Rs 5000 more expensive and had more post operative complications. TEP repair, though expensive, is superior with regard to reduced post operative pain, reduced hospital stay and early return to normal activity, when compared to Lichtenstein's repair.
\end{abstract}

Keywords: TEP, Lichtenstein's, open vs lap hernia, Mesh hernia repair

\section{Introduction}

Of the study of the many operations available in a general surgeon's armamentarium, that of hernia repairs have been written about repeatedly [3]. The rapid changes that have been witnessed in open approach surgeries, prosthetic materials and laparoscopic surgeries have made hernia surgery, a most interesting field of endeavor that demands dedicated work and dedication [4]. A variety of procedures have been described in literature, and are being regularly practiced in institutions around the globe. However there has been no definite consensus about any one being the ideal procedure, as each procedure has its own set of complications, the most significant being recurrence.

In our institution, inguinal hernia repair is one of the most common surgeries performed. The procedures performed most commonly are open Lichtenstein's tension free repair and laparoscopic total extra peritoneal repair. This study aims to find which surgery, among these two, is more advantageous.

\section{Objectives}

1) To compare minimal access laparoscopic hernia surgery (Total Extraperitoneal Repair - TEP) with open Lichtenstein's repair on the basis of i) duration of operation (in mins), ii) post operative pain ( in days), iii) length of hospital stay ( in days), iv) post operative complications like haematoma, seroma, v) time to return to usual activities and vi) cost comparison.

2) To ascertain the number of conversions (defined as a procedure initiated as laparoscopic, but converted to open).

\section{Methodology}

The present study is a prospective study of fifty cases of unilateral inguinal hernia admitted in Yenepoya Medical College and Hospital, Deralakatte, Mangalore, India, during the study period of October 2012 to October 2014. i) The 50 cases were selected on the basis of convenience sampling method. ii) Both direct and indirect unilateral inguinal hernias were selected iii) After pre-operative preparation the patients were selected randomly for open (Lichtenstein's) or laparoscopic (TEP) repair

Types of Outcome Measures: a) Duration of operation (min) b) Conversion (defined as a procedure initiated as laparoscopic, but converted to open and vice versa) c) Haematoma d) Seroma e) Post operative pain f) Length of hospital stay (Days) g) Time to return to usual activities h) Cost comparison

Source of Data/ Sampling Method and Sample Size: 50 cases of unilateral direct or indirect inguinal hernia, adults, admitted to Yenepoya Medical College and Hospital, Mangalore, Karnataka, India.Out of these, 25 were chosen for Lichtenstein's Repair and the remaining 25 for Total Extraperitoneal Repair

Inclusion Criteria: Adults ( $>15$ years) consenting for randomised trials. Unilateral Direct or Indirect Inguinal hernia

Exclusion Criteria: Congenital Hernias, Recurrent Hernias, Bilateral Inguinal Hernias, Obstructed Hernias, Large hernias, People with connective tissue disorders, Patients who have already had lower abdominal surgery, People who are not fit for GA - COPD, Bronchial Asthma etc. (ASA Gr > 3). All patients included in the study were evaluated with a thorough history and physical examination. Routine 


\section{International Journal of Science and Research (IJSR) \\ ISSN (Online): 2319-7064 \\ Index Copernicus Value (2013): 6.14 | Impact Factor (2015): 6.391}

investigations were done - blood investigations plus ultrasound abdomen and prostate specific antigen in the ones whom these were indicated. ECHO was doen for the cardiac evaluation in some patients.

Preoperative treatment and preparation for surgery: Correction of anaemia, Improvement of nutritional status . Treatment of respiratory infections, Breathing exercises, Abstinence from smoking / alcohol, Treatment of urological problems, constipation etc. Type of anaesthesia used was general anaesthesia in case of TEP repair and spinal anaesthesia in case of Lichtenstein's repair. A single dose of prophylactic preoperative antibiotic Cefazolin was given, with one dose post operatively. Analgesics were given post operatively. If epidural analgesia was given, the patient was kept on an NSAID SOS; or alternatively analgesics were given in an injectable form for the first day, and from the second day onwards converted to oral.

\section{Post Operative Care and Complications}

After surgery, all patients were observed carefully for pain, bleeding, urivary retention, wound infection. Pain was assessed using the universal pain assessment tool (WongBaker Facial Grimace Scale). Pain was assessed from 12 hours after the surgery, when the effect of either spinal or general anaesthesia would have worn away. For wound infection, discharge of pus from the operative site, abormal tenderness at the operative site and associated constitutional symptoms like fever etc were looked for Figure 32: Wong Baker Scale. Subcutaneous haematoma was looked for. Seroma in the inguinal region was looked for

Wong-Baker FACES Pain Rating Scale

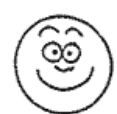

0

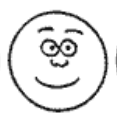

2 HURTS
LITLE BIT

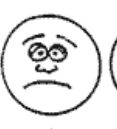
6 HURTS
EVEN MORE

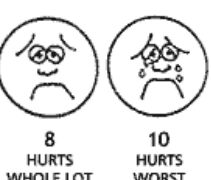

HURTS
From Wong D.L., Hockenberry-Eaton M., Wilson D., Winkelstein M.L., Schwartz P.: Wong's Essentials of Pediatric Nursing, ed. 6, St. Louis, 2001, p. 1301. Copyrighted by Mosby, In

- Urinary retention was termed as inability to urinate spontaneously resulting in catheterization

Discharge: A careful note was kept as to the duration of the post operative pain and the patients were discharged when fit. Follow up was done first after 2 weeks, and checked from wound infection, persistent pain, difficulty in normal activity. Each patient was followed up until 6 months till they could return to normal work. The age, sex incidence, mode of presentation, precipitating factors, surgical treatment, post operative complications, cost of the treatment, hospital stay were all evaluated and compared with standard published literature.

Statistical Analysis: The results of the two types of hernia repairs against the specified outcome measures were analyzed with the following statistical methods: -

Descriptive - Crosstabs - Chi-Square- Independent Samples T Test.

\section{Observation and Results}

In our study, the youngest participant was 23 years old and the oldest was 75 years old. All participants were men.

The youngest patient who underwent Lichtenstein's repair was 26 years old and the oldest was 68 years old.

The youngest patient who underwent TEP repair was 23 years ols and the oldest was 75 years old.

Mean Age and Standard Deviation (comparing cases
who underwent Lichtenstein's Repair and TEP repair)

\begin{tabular}{|c|c|c|}
\hline & Lichtenstein's repair & TEP repair \\
\hline Mean Age ( inyrs) & 47.12 & 53.04 \\
\hline SD & 13.0809 & 13.61825 \\
\hline
\end{tabular}

The $\mathrm{P}$ value is more than 0.05 , hence there is no relation between the ages of the patients and the procedure they underwent : Lichtenstein's repair and TEP repair.

\section{Presenting Symptoms}

Totally 20 patients presented with left sided inguinal hernia as compared to 30 right sided hernias.

Type of Hernia

\begin{tabular}{|c|c|c|}
\hline Valid & Frequency & Percent \\
\hline Direct inguinal Hernia & 27 & 54 \\
\hline Indirect Inguinal Hernia & 23 & 46 \\
\hline Total & 50 & 100 \\
\hline
\end{tabular}

Association of direct and indirect inguinal hernia patients with Lichtenstein's and TEP repair

\begin{tabular}{|c|c|c|c|}
\hline Hernia & Open hernia & TEP & Total \\
\hline Direct & 11 & 16 & 27 \\
\hline Indirect & 14 & 9 & 23 \\
\hline Total & 25 & 25 & 50 \\
\hline
\end{tabular}

$\mathrm{P}$ value is more than 0.05 , hence it is not significant. There is no statistically significant biasing of a particular type of hernia towards a particular procedure.

Duration of symptoms

\begin{tabular}{|c|c|c|}
\hline Valid & Frequency & Percentage \\
\hline$<1 \mathrm{yr}$ & 22 & 44 \\
\hline$>1 \mathrm{yr}$ & 28 & 56 \\
\hline Total & 50 & 100 \\
\hline
\end{tabular}

A higher number of patients presented with complaints for more than 1 year.

Association between smoking and incidence of hernia

\begin{tabular}{|l|l|l|l|}
\hline & Direct hernia & Indirect hernia & Total \\
\hline Smoker & 19 & 9 & 28 \\
\hline Non-smoker & 8 & 14 & 22 \\
\hline Total & 27 & 23 & 50 \\
\hline
\end{tabular}

$\mathrm{P}$ value is $0.03(<0.05)$, hence significant. This implies that smokers, in this study, had an increased incidence of direct inguinal hernia.

Precipitating factors
\begin{tabular}{|c|c|c|}
\hline Valid & Frequency & Percent \\
\cline { 2 - 4 } Strenuous work only & 23 & 46 \\
\cline { 2 - 4 } Bronchial asthma only & 2 & 4 \\
\hline BPH only & 3 & 6 \\
\hline Constipation only & 2 & 4 \\
\hline COPD only & 1 & 2 \\
\hline Smoker only & 11 & 22 \\
\hline More than one factor & 8 & 16 \\
\hline Total & 50 & 100 \\
\hline
\end{tabular}

\section{Volume 5 Issue 5, May 2016}




\section{International Journal of Science and Research (IJSR) \\ ISSN (Online): 2319-7064}

Index Copernicus Value (2013): 6.14 | Impact Factor (2015): 6.391

The most important precipitating factor was strenuous work, with isolated strenuous work accountng for $46 \%$ of the cases.

\section{Duration of surgery in minutes}

\begin{tabular}{|c|c|c|c|}
\hline Type of Surgery & $\mathrm{N}$ & Mean(min) & SD \\
\hline Lichtenstein's & 25 & 62.2 & 13.9254 \\
\hline TEP & 25 & 72.4 & 10.3199 \\
\hline Total & 50 & & \\
\hline
\end{tabular}

$P$ value is 0.005 , hence significant. Hence there is an increase in the duration of repair of unilateral TEP repair compared to the Lichtenstein's repair. This may be attributed to the learning curve.

\section{Duration of post operative pain in days}

\begin{tabular}{|c|c|c|c|}
\hline Surgery & $\mathrm{N}$ & Mean days & SD \\
\hline Lichtenstein's & 25 & 2.8 & 1.4434 \\
\hline TEP & 25 & 1.48 & 0.6532 \\
\hline Total & 50 & & \\
\hline
\end{tabular}

\section{Duration of post operative pain (in days)}

$\mathrm{P}$ value is $<0.001$, hence significant. Thus there is a definite reduction in the duration of post operative pain (in days) following a TEP repair than a Lichtenstein's repair.

Duration of post operative hospital stay ( in days )

\begin{tabular}{|c|c|c|c|}
\hline Surgery & N & Mean days & SD \\
\hline Lichtenstein's & 25 & 5.12 & 2.242 \\
\hline TEP & 25 & 2.6 & 0.866 \\
\hline TOTAL & 50 & & \\
\hline
\end{tabular}

$P$ value is $<0.001$, hence significant. Hence patients who underwent Lichtenstein's repair stayed for a longer time in the hospital compared to those who underwent TEP repair. who have undergone TEP repair can go to normal work earlier than those who underwent Lichtenstein's repair.

\section{Discussion}

The subject of repair of inguinal hernia has been full of controversy ever since Eduardo Bassini of Padua University described his method of repair in the manuscript 'Radical Cure of Inguinal Hernias' way back in 1887. The fact that more than a hundred repairs have been described for inguinal hernia and practised at some time or the other over the past century are a testimony to the fact that none has been considered distinctly superior to the others. In recent years, however, the use of mesh for repair of inguinal hernia has become a norm. Reduction in the recurrence rate from more than $15 \%$ with tissue repairs to less than $1 \%$, reduction in the postoperative pain and a shorter convalescence have all contributed to the popularity and widespread use of the tension- free mesh repairs. The laparoscopic repair of inguinal hernia, a relatively newer modality in the armamentarium of the surgeon, has been around for around two decades. Although perhaps not practised as widely as laparoscopic cholecystectomy is for gallstone disease, laparoscopic repair of inguinal hernia has established its rightful place in the surgical practice [48].

Out of the two types of laparoscopic hernia repair followed most commonly, TAPP and TEP, we have exclusively performed TEP repairs in our patients. In TAPP the surgeon goes into the peritoneal cavity and places a mesh through a peritoneal incision over possible hernia sites. TEP is different as the peritoneal cavity is not entered and mesh is used to seal the hernia from outside the thin membrane covering the organs in the abdomen (the peritoneum) [49].

\section{Conclusion}

Cost in Rupees

\begin{tabular}{|c|c|c|c|}
\hline Surgery & $\mathrm{N}$ & Mean cost in Rupees & SD \\
\hline Lichtenstein's & 25 & 3500 & 640.31 \\
\hline TEP & 25 & 8068 & 1074.99 \\
\hline Total & 50 & & \\
\hline
\end{tabular}

$P$ value is $<0.001$, hence significant. This implies that there is an increased expenditure associated with TEP repair compared to Lichtenstein's repair.

\section{Complications}

\begin{tabular}{|c|c|c|c|}
\hline \multicolumn{4}{|c|}{ COMPLICATIONS } \\
\hline Surgery & Hematoma & Seroma & Total \\
\hline Lichtenstein's & - & - & - \\
\hline TEP & - & 2 & 2 \\
\hline TOTAL & - & 2 & \\
\hline
\end{tabular}

There were only two cases of seromas, in case of TEP repair.

Time interval of returning to normal work ( in days)

\begin{tabular}{|c|c|c|c|}
\hline Type of surgery & $\mathrm{N}$ & $\begin{array}{c}\text { Mean time interval (in days) } \\
\text { of returning to work }\end{array}$ & $\mathrm{SD}$ \\
\hline Lichtenstein's repair & 25 & 43.72 & \multirow{}{*}{13.8} \\
\hline TEP & 25 & 25.6 & \multirow{2}{*}{12.1} \\
\hline Total & 50 & & \\
\hline
\end{tabular}

$\mathrm{p}$ value is less than 0.05 , hence significant. Hence, patients
The present study is a comparison of the effectiveness and complications of the Lichtenstein's tension free repair and the Total Extraperitoneal (TEP) Repair.

All the patients were carefully monitored from the time of admission till discharge, and the parameters pertaining to the study noted. We found that there is a marked reduction in post operative pain in laparoscopic hernia repair compared to hernioplasty. Post operative stay is less in TEP repair. Post operative return to work is earlier in TEP compared to Lichtenstein's repair- Laparoscopic hernia repair is quite expensive compared to hernioplasty. The patients have been followed up for noting any long term complications and also for the time taken to return to usual pre-hernia lifestyle. There were a few drop outs, people who failed to follow up.

There were a few limitations to the study; the Wong Baker scale to assess pain was subjective and does not bring into account the level of tolerances of different patients. All patients could not be followed up on a long term basis.

There is no universal repair for groin hernia and no two surgeons would disagree on that point. The availability of such an array of surgical techniques in the treatment of groin hernias is bound to confuse the younger surgeon. All techniques will have proponents as well as opponents. This

\section{Volume 5 Issue 5, May 2016}




\section{International Journal of Science and Research (IJSR) \\ ISSN (Online): 2319-7064}

Index Copernicus Value (2013): 6.14 | Impact Factor (2015): 6.391

is where the practice of evidence based medicine is very crucial and one should closely follow up the long term results of the newer procedures.

TEP repair, though expensive, is superior with regard to reduced post operative pain, reduced hospital stay and early return to normal activity.

\section{References}

[1] Legutko J, Pach R, Solecki R, Matyja A, Kulig J. The history of treatment of groin hernia. Folia Med Cracov. 2008;49(1-2):57-74.

[2] Van Hee R. History of Inguinal Hernia Repair. Jurnalul de Chirurgie, Iaşi, 2011, Vol. 7, Nr. 3 [ISSN 1584 9341]

[3] RutkowIM . A selective history of groin herniorraphy in the $20^{\text {th }}$ century. SurgClin North Am. $1993 ; 73: 395$ 411.

[4] Bendavid R. Complications of groin hernia surgery. SurgClin North Am. 1998; 78: 1089-1103.

[5] Skandalakis MC, Skandalakis JE. The personal and professional life of John Hunter. J Med Assoc Ga. 1991; 80-445.

[6] Castiglioni A. A history of medicine. New York: Alfred A, Knopf 1958. Krumbhaar EB, translator

[7] Garrison FH. An introduction to the history of medicine. Philadelphia: WB Saunders, 1929.

[8] Haeger K. The illustrated history of surgery. London : Harold Starke, 1988.

[9] Halsted WS. The cure of the more difficult as well as the simpler inguinal ruptures. Bull Hopkins Hosp. 1903; 14: 208.

[10]Last RJ. Anatomy regional and applied . Baltimore Williams \& Wilkins, 1972: 507.

[11] Nyhus LM. Editorial comment . In Nyhus LM, Condon RB, eds. Hernia . $2^{\text {nd }}$ ed. Philadelphia : JB Lippincott, 1978;

[12]Lucas Championniere J. ChirurgieOperatoire; cure radicale des hernies; avec une etude statistique de deux cent soixante - quinze operations et cinquante figures intercaleesdans le texte .Paris :Rueff et ciet , 1892.

[13] Bassini E. Nuovometodo per la curaradicale dell 'erniainguinale. AtticongrAssoc Med Ital 1887; 2: 179.

[14] Musgrove JE, McCready FJ. The Henry approach to femoral hernia. Surgery, 1948; 26: 608.

[15] McEvedy BV. Inguinal hernia: the rectus sheath approach. West Afr Med J. 1958; 7: 106.

[16] Shouldice EE. Surgical treatment of hernia. Ont Med rev. $1945 ; 12: 43$.

[17] Simons et al. European Hernia Society guidelines on the treatment of inguinal hernia in adult patients. Hernia , Aug2009; 13 (4): 343-403.

[18] Gilbert Al. sutureless repair of inguinal hernia. Am J Surg. 1992; 163: 331.

[19] Arregui ME. Laparoscopic preperitonealherniorraphy. Paper presented at: Annual meeting of the society of American Endoscopic Surgeons. 1991; Monterey, C.A.

[20] SurgLaparoscEndosc. 1992 Mar;2(1):53-8.Laparoscopic mesh repair of inguinal hernia using a preperitoneal approach: a preliminary report. Arregui ME, Davis CJ, Yucel O, Nagan RF

[21] Abrahamson J. Hernias. Maingot's Abdominal
Operations $10^{\text {th }}$ ed. McGraw Hill, 2001; 479-580.

[22] Williams NS, Bulstrode CJK, o'Connell PR. Hernias, umbilicus and abdominal wall. Bailey and Love's Short Practice of Surgery, $25^{\text {th }}$ ed. London ,Hodder Arnold, 2008; 969-77.

[23] Sinnatamby CS. Anterior abdominal wall . Last's anatomy regional and applied, $10^{\text {th }}$ ed. Churchill Livingstone, 2000; 215-226.

[24] Chaurasia BD. Anterior abdominal wall, Human Anatomy Regional and Applied, $2^{\text {nd }}$ ed. CBS Publishers, 1991; 163-180.

[25] Standring S. Muscles of Abdomen.Gray's Anatomy the Anatomical Basis of Clinical Practice, $40^{\text {th }}$ ed. Elsevier, 2008

[26] Townsend MC, Beauchamp RD, Evers BM, Mattox KL, Malangoni MA, Rosen MJ. Hernias, Sabiston Textbook of Surgery, $19^{\text {th }}$ ed. Elsevier Saunders, 2012 ; 1124-6.

[27]Decker GAG, du Plessis DJ. The groin and scrotum. Lee McGregor's Synopsis of Surgical Anatomy $.12^{\text {th }}$ ed, Varghese Publishing House , 1999; 118-136.

[28] Sherman V. Inguinal hernias, Schwartz's Principles of Surgery, $9^{\text {th }}$ ed. McGraw Hill, 2008; 2520-62.

[29] Rutkow IM. Surgical Operations in the United States Arch Surg. 1997; 132: 983.

[30] Bhat MS. SRB's Manual of Surgery, $4^{\text {th }}$ ed. Jaypee Brothers Medical Publishers (P) Ltd, 2013; 801-2.

[31]Zollinger RM Jr.: An updated traditional classification of inguinal hernias. Hernia 8:318, 2004

[32] Amado WJ. Anesthesia for henia surgery. SurgClin North Am. 1993; $73: 427$ - 437.

[33] Russell RCG, Williams NS, Bulstrode CJK. Hernias, umbilicus and abdominal wall. Bailey and Love's Short Practice of Surgery, $24^{\text {th }}$ ed. London, Arnold, 2004; 1272-93.

[34]Das S. A manual on clinical surgery. Calcutta $6^{\text {th }}$ ed 2004; 436-450.

[35] Clain A. Demonstration of physical signs in clinical surgery. $17^{\text {th }}$ ed. $1992 ; 260-272$.

[36] Browse NL. An introduction to the symptoms and signs of surgical diseases. $2^{\text {nd }}$ ed. ELBS, $1991 ; 310-321$.

[37] Devlin HB. Inguinal hernia in adults. In: Carter D, Russell RCG, Pitt HA. Atlas of General Surgery. $3^{\text {rd }}$ ed. London : Arnold 1996; 38-49.

[38] Johnstone JMS, Rintoul RF. Abdominal hernias. Farquharson's Textbook of Operative Surgery. $8^{\text {th }}$ ed. Churchill Livingstone 2000; 523-546.

[39] Abrahamson J. Hernias. Maingot's Abdominal Operations $11^{\text {th }}$ ed. McGraw Hill, 2001; 221.

[40] Shouldice EE. The treatment of hernia. Ontario Med Rev 1953;20:670

[41] Rutkow IM, Robbins AW. "Tension free" inguinal herniorraphy : a preliminary report on the mesh plug technique. Surgery 1993 Jul; 114(1): 3-8.

[42] Chevrel JP, Gatt MT. The treatment of neuralgias following inguinal herniorraphy: A report of 47 cases. Postgrad Gen Surg. 1992; 4 : 142-147.

[43] Geir WP, Singh K, Gillian GK. An algorithm for the treatment of chronic pain after inguinal herniorraphy. In :Nyhus LM, Condon RE, eds Hernia $5^{\text {th }}$ ed. Philadelphia: JB Lippincott, 2000; 307-316.

[44] Cunningham J. The physiology and anatomy of chronic pain after inguinal herniorraphy. In :Nyhus LM, 
Condon RE, eds. Hernia $5^{\text {th }}$ ed. Philadelphia: JB Lippincott, 2000; 297- 306.

[45] Celdran A, Frieyro O, Souta JL, Villar S. Study of recurrences after anterior open tension free hernioplasty. In :Nyhus LM, Condon RE, eds. Hernia $5^{\text {th }}$ ed. Philadelphia: JB Lippincott, 2000; 4: 85-87.

[46] Richards AJ. Cord and testicular complications of groin herniorraphy. In :Nyhus LM, Condon RE, eds. Hernia $5^{\text {th }}$ ed. Philadelphia: JB Lippincott, 2000; 291-6.

[47] Kugel RD. Minimally invasive, nonlaparoscopic, preperitoneal, and sutureless, inguinal herniorrhaphy. Am J Surg178:298,1999

[48] Chowbey PK, Pithawala M, Khullar R, Sharma A, Soni $\mathrm{V}$, Baijal M. Complications in groin hernia surgery and the way out. J Minim Access Surg. Sep 2006; 2(3): 174177.

[49] Bhandarkar DS, Shankar M, Udwadia TE. Laparoscopic surgery for inguinal hernia: Current status and controversies. J Min Access Surg 2006;3:178-86.

[50] McCormack K, et al. Laparoscopic techniques versus open techniques for inguinal chernia repair. Cochrane Database Syst Rev 2003; (1): CD001785.

[51]Eklund A et al. Short-term results of a randomized clinical trial comparing Lichtenstein open repair with totally extraperitoneal laparoscopic inguinal hernia repair. Br J Surg. 2006 Sep;93(9):1060-8.

[52] Eker $\mathrm{HH}$ et al. Randomized clinical trial of total extraperitoneal inguinal hernioplastyvs Lichtenstein repair: a long-term follow-up study. Arch Surg. 2012 Mar;147(3):256-60. doi: 10.1001/archsurg.2011.2023

[53] Kouhia ST et al. Lichtenstein hernioplasty versus totally extraperitoneal laparoscopic hernioplasty in treatment of recurrent inguinal hernia--a prospective randomized trial. Ann Surg. 2009 Mar;249(3):384-7. doi: 10.1097/SLA.0b013e318196d0b0.

[54] Gokalp A, Inal M, Maralcan G, Baskonus I. A Prospective Randomized Study of Lichtenstein Open Tension-free Versus Laparoscopic Totally Extraperitoneal Techniques for Inguinal Hernia Repair. Actachirbelg, 2003, 103, 502-506.

[55] Bay-Nielsen $M$ et al. Convalescence after inguinal herniorraphy. Br J Surg. 2004; 91: 362-367.

[56]Liem MSL, Duyn EBD, Graaf V, van Vroonhoen TJMV. Recurrences after Conventional Anterior and Laparoscopic Inguinal Hernia Repair. Ann Surg. 2003; 237: 136-141.

[57]Laparoscopic versus open repair of groin hernia: a randomised comparison. The MRC Laparoscopic Groin Hernia Trial Group. Lancet. 1999 Jul 17;354(9174):185-90. 